\title{
A exterritorialidade como condição do apátrida transcendental. Sobre Siegfried Kracauer e Georg Lukács
}

Carlos Eduardo Jordão Machado 


\section{Resumo}

Pouco se discutiu da recepção (sempre crítica) de Siegfried Kracauer das obras do jovem Lukács e do posicionamento (indireto) de Kracauer diante do cinema alemão à época do "Debate sobre o expressionismo" de a Linkskurve (1931-33) à revista moscovita (1938) Das Wort. Trata-se de determinar a peculiaridade da posição de Kracauer diante do expressionismo alemão e de entender sua interpretação da modernidade.

\section{Palavras-chave}

debate sobre expressionismo; crítica da ratio; vanguardas históricas; cinema alemão; realismo; realista "curioso"; 1848 francês.

\section{Abstract}

I present Kracauer's original critical analysis of aesthetic modernity, above all of the German Expressionism to understand his (indirect) relation with the Discution about Expressionism (1938) and to make clear the particularity Kracauer's position about modernity and the historical avantgarde.

\section{Keywords}

Discution about Expressionism; historical Avantgarde; critic of the ratio and the world of things; German Film; Realism; "curious" realist; the french 1848 . 
$\mathbf{P}$ ouco se discutiu sobre a recepção (sempre crítica) de Siegried Kracauer das obras do jovem Lukács - de Theorie des Romans [A teoria do romance] e de Geschichte und Klassenbewusstsein [História e consciência de classe] e do posicionamento (indireto) estético-político de Kracauer diante do cinema alemão à época do "Debate sobre expressionismo" de a Linkskurve (1931-33) à revista moscovita (1938) Das Wort. Em geral se valoriza a importância de Geschichte und Klassenbewusstsein como obra que deu início a uma tradição de pensamento que Merleau Ponty denominou "marxismo ocidental", mas se sabe muito pouco da repercussão dos escritos anteriores de Lukács de Entwicklungsgeschichte des modernen Dramas [História do desenvolvimento do drama moderno], passando pela Die Seele und die Formen [A alma e as formas] à Theorie des Romans. Basta citar a importância deste último na obra de juventude de Herbert Marcuse Der Kunstlerroman [O romance do artista\} (1922) e, sobretudo, praticamente no conjunto da obra deste, que Adorno caracterizou de "Der wunderliche Realist" [O realista curioso]', Siegfried Kracauer.

Recapitulando um pouco da trajetória de Lukács, como é sabido, com a eclosão da I Guerra Mundial, Lukács decide interromper a redação de sua Heidelberger Kunsphilosophie [A filosofia da arte de Heidelberg] para iniciar um novo livro, conforme se lê na sua carta a Paul Ernst: "Dedico-me finalmente agora ao meu novo livro sobre Dostoiévski... Este conterá muito mais do que sobre Dostoiévski,

1. ADORNO, Th. Noten zurLiteratur. Frankfurt aM: Suhrkamp, 1981, pp. 388-408. 
boa parte de minha ética metafísica e filosofia da historia etc."2 Desse projeto apenas a primeira parte foi publicada, Die Theorie des Romans. Ein geschichtsphilosphischer Versuch über die Formen der grossen-Epik, primeiramente na revista Zeitschrift für Ästhetik und Allgemeine Kunstwissenschaft em 1916 e como livro em 1920. Nesse livro o mundo grego é descrito como um mundo homogêneo, que surge como um dos poucos instantes "bem-aventurados" da história, como também em Hegel, no qual as grandes formas (épica, tragédia e filosofia) se desdobram, obedecendo uma necessidade $a$ priori, ao contrário do mundo moderno, no qual se contrapõem a experiência histórica individual e o seu significado. O homem moderno vive numa condição de "sem-teto transcendental". O romance é, para Lukács, nas palavras de Fichte, "a forma da época da pecaminosidade completa"3.

Sua forma épico-ensaísta provocou reações contrapostas: de um lado aquelas que vão reagir negativamente ou simplesmente vão odiar o livro como Max Weber, que incentivava Lukács em sua Livre-Docência (Habilitation) em Heidelberg, e de outro aquelas que vão reagir com fascínio como Ernst Bloch, nas cartas, Siegfried Kracauer e Margarete Susmann entre outros, em resenhas. Para se ter uma visão da recepção da obra do jovem Lukács na época na Hungria, Alemanha e França, foi publicado em 1988, Der junge Lukács im Spiegel der Kritik [O jovem Lukács no espelho da crítica], pelo Lukács Archivum de Budapeste, graças ao paciente trabalho de Julia Bendl e Árpád Timár. Aqui me interessa destacar as duas resenhas que Kracauer escreveu logo depois da publicação da Teoria do romance em livro.

2. Carta a Paul Ernst de 03/ 1915 in LUKÁCS, G. Briefwechsel 1902-17. Éva Karádi und Éva Fekete (Hg.). Stuttgart:Metzler, 1982, p.345.

3. LUKÁCS. G. Theorie des Romans. München: DTV, 1994. Veja tambem: MACHADO,C.E..J. "Die 'zweite Ethik als Gestaltungapriori eines neuen Epos" in BENSELER, F. JUNG. W. Jahrbuch der Internationalen Georg-LukácsGesellschat. Bern: Peter Lang, 1997, pp.73-116. e KARADI, E. "Lukács'Dostojewski-Projekt", Ibid, pp. 117-132. MACHADO.C.E.J. As formas e a vida. Estética e ética no jovem Lukács (1910-18). São Paulo: Ed. UNESP, 2004. 


\section{Um ético metafísico}

A primeira resenha foi publicada na Die Weltbühne, em setembro de 1921 e a segunda um mês depois na Neue Blätter für Kunst und Literatur. Na verdade trata-se de um mesmo texto, sendo o primeiro uma versão com cortes ${ }^{4}$. A recepção de Kracauer da Teoria do romance é significativa para se compreender o seu próprio desenvolvimento intelectual, talvez dos escritos de Lukács aquele que mais o influenciou de modo duradouro, como pretendo mostrar. Não se trata de uma relação mestre-discípulo, mas de uma maneira de delimitar claramente a posição individual e o desenvolvimento intelectual de cada um. Kracauer havia iniciado naquele ano a se dedicar integralmente ao ofício de escritor, tornando-se colaborador regular do jornal Frankfurter Zeitung, tendo abandonado sua profissão de arquiteto, profissão que, diga-se de passagem, detestava. Julia Bendl e Inka Mülder-Bach sugerem que Kracauer possa ter conhecido pessoalmente Lukács antes de 1914 por intermédio de Georg Simmel, mas o fato não pôde ser confirmado até hoje. Simmel foi figura de proa na formação de ambos os pensadores. Lukács conhecia os trabalhos de Kracauer por intermédio de Ernst Bloch, se chegou a lê-los também não se pode comprovar. $O$ certo é que Kracauer acompanhou com atenção o desenvolvimento teórico de Lukács ao longo dos anos vinte e trinta do século passado como um modo de delimitar sua própria posição ${ }^{5}$.

Kracauer começa ressaltando a incomparável incisão do livro no que diz respeito a apresentar uma diagnose de época, na forma de uma construção histórico-filosófica: "O filósofo, Georg von Lukács, apresentou, em um pequeno livro, a situação histórico-filosófica de nossa época com uma incisão inaudita. Em geral quais épocas são

4. A segunda versão, completa, foi reeditada aos cuidados de Inka Mülder-Bach em 1990. KRACAUER, S. Schriften, 5-1. Aufsätze 1915-1926. Frankfurt aM: Suhrkamp, 1990, pp. 117-123.

5. Cf. MÚLDER-I. "Siegfried Kracauer Antwort auf Lukács - Versuch einer Rekonstruktion" (dat.), p.1. 
possíveis os grandes romances? - assim formula o pensador a questão fundamental e que é respondida a partir de uma metafísica na qual engloba a ânsia fervorosa do presente por uma reaparição de Deus no mundo." ". A "situação histórico-filosófica de nossa época" vai de encontro ao modo mesmo como Kracauer avaliava sua própria posição diante do presente como um "Zersetzungsprozess". Um processo de desagregação que abre um abismo entre indivíduo e mundo, entre sujeito e objeto, processo este que, segundo Kracauer, Lukács caracteriza com uma "incisão inaudita". Como enfatiza em seguida: "Apenas quando o sentido se volatiliza do mundo, abrindo um abismo entre alma e forma, entre interior e exterior é chegada a hora histórica do grande romance. Este é 'expressão da condição do sem-teto transcendental'." . Da condição do "sem-teto transcendental" ou do "apátrida transcendental" (transzendentale Heimatlosigkeit), Kracauer tira conseqüências para criticar os limites das ciências, inspiradas no pensamento puro (matemático-formal), incapazes de responder com sentido humano às tarefas colocadas pelo presente. "A filosofia do último século é uma tentativa única de lançar uma ponte sobre o abismo que se abriu com o desaparecimento do sentido capaz de envolver a realidade conjunta, e que separa irrevocavelmente a informe multiplicidade do existente -convertida em um ser em-si - em relação ao espírito que a forma, o caos do sujeito racional; é uma tentativa, que deve fracassar necessariamente, pois é levada a cabo com os meios insuficientes do pensamento puro"8. $\mathrm{Na}$ ocasião em que Kracauer redige seus comentários à Teoria do romance, estava elaborando seu primeiro livro publicado (1922), Soziologie als Wissenschaft [A sociologia como ciência], no qual incorpora na sua crítica esse diagnóstico de Lukács sobre o mundo moderno. Como observou Nia Perivolaropoulou; "Kracauer estabelece um paralelo, se apoiando na Teoria do romance de Lukács,

6. KRACAUER, S. Schriften 5-1, p.118.

7. BENDL, J u. ÁRPAD, T. Der junge Lukács im Spiegel der Kritik. Budapest: Lukács Archiv, 1985, p.314.

8. KRACAUER, S. Schriften 5-1, p.117. 
entre a gênese das ciências modernas e o desaparecimento de uma época impregnada de sentido(sinnerfüllten Epoche)"9.

Apesar de se tratar de uma mera resenha, Kracauer dá atenção não apenas à diagnose de época formulada por Lukács, questão para ele a mais importante, mas também ao modo de construção de sua análise imanente que apreende a estrutura interna do romance, ao seu mundo como sendo um processo, uma "infinitude sem margem", ao papel central da ironia diante da "má infinitude" do existente como sendo o único meio artístico possível ao "indivíduo problemático" diante do caos de um mundo tornado sem sentido: "Sua estrutura é resultado da própria essência do romance. Lukács caracteriza o mundo do romance como uma infinitude sem margem, demonstrando que o sujeito poético deve se apoiar no meio artístico da ironia para, por meio deste não se importar [Sichhinwegsetzen] com a própria interioridade, alcançar a realidade separada de seu eu, e caracteriza o herói do romance como o indivíduo problemático que vaga pelo mundo tornado caos à procura de sentido"io.

Apesar de Kracauer fazer restrições à tipologia do romance moderno, por considerá-la forçada (gezwungen] - o que está plenamente de acordo com as palavras do próprio Lukács no Prefácio de 1962, "uma camisa de força" [eine Zwangsjacke]"1 - , ressalta sua interpretação do romance de educação, representado pelo Wilhelm Meister de Goethe, considerando-a magistral e definitiva: "Como Lukács revela toda a estrutura necessária do romance de educação [Erziehungsroman] de Goethe, por meio de sua análise profundamente incisiva, é simplesmente magistral e definitiva [meisterhaft und endgultig]"12. Em relação ao romance da "desilusão romântica", Kracauer dá pouca atenção à figura de Flaubert, particularmente à $L$ 'éducation sentimentale, à importância

9. "Les mots de l'histoire et les images de cinema"in PERIVOLAROPOULOU, N. e DESPOIX, Ph. Culture de masse et modernité. Siegfried Kracauer. Sociologue, critique, écrivain. Paris: Sciences de l'homme, 2001, pp. 249-250.

10. BENDL, J. U. TIMAR, A., pp.314.

11. LUKACS. G. Theorie des Romans, p. 7.

12. KRACAUER, S. Schriften 5-1, p.121. 
da recordação (Erinnerung) na estruturação da totalidade da narrativa e como sintoma da perda da experiência - se não há mais experiência, narrar o que? - mais do que isto, da durée, antecipando a Recherche du temps perdu de Marcel Proust, conforme o próprio Lukács reconhece no Prefácio citado de1962.

Interessante é como Kracauer destaca a interpretação de Lukács dos romances de Tólstoi e Dostoiévski, e particularmente deste último. Como observa Ernst Bloch em uma carta a Lukács: "tudo termina em Dostoiévski"13. A visão de Kracauer não é diferente: "Lukács concede um lugar próprio à obra de Tolstoi em sua tipologia.[...] "Apenas com Dostoiévski - e com uma significativa referência a ele termina o livro - torna-se de novo o sentido totalmente imanente à vida. Ele realizou com seus épos a ruptura com a época 'da pecaminosidade completa e pertence diretamente a um novo mundo impregnado de sentido, como os que Lukács celebra em Homero ou em Dante"14. Mas se mostra cético em relação à essa possibilidade de um novo épos para o mundo ocidental: "É possivel que o mundo de Dostoiévski signifique, antes de tudo, o tornar-se corpóreo de um sentido válido para o povo russo. O Ocidente, no entanto, deveria realmente e de modo irrefreável ter-se decaído antes que no épos russo de Dostoievski pudesse vivenciar o preenchimento da sua nostalgia originária. A este Ocidente, que peregrinou e dominou a realidade incomensurável como nenhuma cultura anterior, o épos homérico e a estrutura arquitetônica estão de vários pontos de vista mais próximos do que a obra de Dostoievski, que decerto amplia o inteiro reino da alma num cosmo impregnado de sentido que, no entanto, não configura aquela ampla multiplicidade extensiva da totalidade fechada que foi uma vez propriedade conquistada pela Europa"15.

Kracauer chama atenção para os elementos essenciais da construção interpretativa do livro, a significação do "demonismo", da "ironia", mas o que lhe fascinou foi sem dúvida o diagnóstico de

13. BLOCH. E. Briefe 1903-75. Frankfurt aM; Suhrkamp. 1985, B.1, p. 178.

14. KRACAUER, S. Schriften 5-1, p.121.

15. Ibid.p.122.

Significaçăo. 27 • 188 
época, ao definir o presente como expressão "da pecaminosidade completa". Por último faz restrições também ao estilo expositivo do livro: "Pode-se apenas lamentar que o livro foi escrito numa linguagem que por causa de sua dificuldade permite $o$ acesso a este somente a poucos homens"16.

Se para o jovem Lukács, a crítica de Marx à religião está ainda sob a influência da cultura do esclarecimento; crítica que não vê nada além do céu estrelado de Kant que brilha apenas na escura noite do conhecimento puro. Seu raio de luz não ilumina mais os passos de nenhum caminhante solitário. Para ele, a cultura do socialismo carece de uma força ética, como ocorria no cristianismo primitivo, questão expressa no seu ensaio "Cultura estética". Kracauer expressa algo semelhante em sua resenha: "Mesmo o movimento socialista [sozialistische Bewegung] poderia bastar para confirmar o desgarre de nosso tempo; às relações econômicas às quais aspira não podem preencher por si mesmas os vínculos religiosos, de modo que, no final de contas, segue deixando-nos abandonados na solidão e na condição de apátridas"(p.117). Nos termos do jovem Lukács, a desilusão de um mundo sem Deus não pode ser de modo algum fundamento em uma nova moral. Pois, um ateu ocidental sabe apenas que Deus é um equívoco, um equívoco esclarecido; seu mundo é desiludido e seu tipo de indivíduo, egoísta. O ateísmo europeu ocidental, englobando até mesmo o do jovem Marx, não sabe mais dar resposta à pergunta de como se pode viver. Kracauer, neste período de sua trajetória intelectual, se coloca também esse mesmo tipo de questionamento existencial influenciado em boa medida pela leitura de Kierkegaard - autor chave, não só para o autor de Die Theorie des Romans, mas também na formação intelectual de Kracauer, sobretudo, como pretendo mostrar, em Der Detektivroman. Ambos expressam a condição de "apátridas transcendentais".

Como lembra o amigo de Kracauer, Leo Löwenthal, com quem manteve uma intensa correspondência do início dos anos vinte até o fim da vida de Kracauer, em seu ensaio de 1990, a propósito do

16. Ibid. p.121. 
Simpósio de homenagem Kracauer realizado na Columbia University: "Wenn ich an Friedel denke..." [Quando me lembro de Friedel ${ }^{17} . .$. ] Em outubro de 1923, por motivo do casamento de Löwenthal, Kracauer e Adorno enviam-lhe um cartão de felicitações com um remetente extremamente curioso: "Quartel General do escritório de previdência aos apátridas transcendentais" e com a anotação de Adorno: "Kracauer e Wiesengrund. Direção Geral do serviço de proteção aos sem-teto transcendentais". O que Löwenthal comenta não sem razão: "Era, naturalmente, uma referência à Teoria do romance de Lukács. Pois `sem-teto tanscendental' permaneceu uma categoria adequada para Kracauer"18.

\section{Crítica da ratio}

Nesse período Kracauer passava por uma intensa transformação intelectual, se por um lado é extremamente simpático ao livro do jovem Lukács, reage de modo crítico à obra de Ernst Bloch, Thomas Múnzer als Theologe der Revolution[Thomas Münzer como teólogo da revolução], numa resenha publicada de 1922, "Prophetentum"19. Para Kracauer o livro de Bloch carece da densidade analítica de Theorie des Romans, na sua tentativa de conciliar uma perspectiva comunista e uma visão quiliástica da história. Apesar dessas diferenças de opinião, Bloch e Kracauer se transformam em bons amigos e o autor de Geist der Utopie [O espírito da utopia](1918) torna-se um importante interlocutor de Kracauer nos anos vinte e trinta, período de transição ideológica e de radicalização política de Kracauer. É, sobretudo, por mediação de Bloch que Kracauer acompanha a produção intelectual de Lukács. O caráter de transição deve ser ressaltado. Seus ensaios de acerto

17. Os amigos mais próximos de Kracauer, como Löwenthal, se referiam a ele com a alcunha, Friedel.

18. LÖWENTHAL, L. KRACAUER, S. In Steter Freundschaft. Briefwechsel 19211966. Herausgegeben von Peter-Erwin Jansen und Christian Schmidt. Springe: Klampen, 2003, p. 276.

19. KRACAUER, S. Schriften 5-1, pp. 196-204. 
de contas ideológico com a religião e a ciência são significativos: no primeiro caso, sua leitura da obra de Max Scheler em Catolicismo e relativismo ${ }^{20} 1921$ ), sua interpretação minuciosa dos escritos de Max Weber e Ernst Troeltsch em A crise da ciência ${ }^{21}$ (1923) e, sobretudo, sua ruptura com o círculo formado por Martin Buber e Franz Rosenzweig, no artigo Bíblia em alemão $o^{22}$ (1926), no qual, testemunha sua áspera crítica à tradução realizada por ambos do Velho Testamento para o alemão, evidenciando assim seu distanciamento radical de qualquer tentativa de refundar uma visão teológica no presente.

Não podemos esquecer, para se ter uma idéia de que modo Kracauer se transforma num crítico materialista da cultura sui generis, o ensaio emblemático, "O ornamento da massa", nele deixa clara sua posição metodológica diante da história: "O lugar que uma época ocupa no processo histórico pode ser determinado de modo muito mais pertinente a partir da análise de suas discretas manifestações de superfície do que dos juízos da época sobre si mesma. (...) O conteúdo fundamental de uma época e os seus impulsos desprezados se iluminam reciprocamente"23. Nesse trecho, salta aos olhos não só sua originalidade teórica diante da história como também sua atenção para com os fenômenos de superfície de uma época, manifestações em princípio desprezíveis, sem importância para uma historiografia tradicional - diferenciando aqui radicalmente do conceito de totalidade de Geschichte und Klassenbewusstsein. Por outro lado, se aproxima de Lukács ao equiparar a racionalização das formas de vida (Weber) ao processo de reificação social (Marx). Para Kracauer, a ratio abstrata é uma das debilidades do capitalismo, pois "não racionaliza muito, mas muito pouco"24. Começa com a imagem das Tillergirls, dançarinas de revistas dos anos vinte, com seu

20. KRACAUER, S. Schriften 5-1, pp. 123-130.

21. KRACAUER, S. Schriften 5-1, pp. 212-221.

22. KRACAUER, S. Schriften 5-1, pp. 355 367.

23. KRACAUER, S. Das Omament der Masse. Frankfurt aM: Suhrkamp, 177, S. 50. $O$ ornamento da massa. Trad. Carlos Eduardo J. Machado e Marlene Holzhausen. São Paulo: Cosac \& Naify, 2007.

24. Ibid. p. 56. 
movimento mecânico e impessoal, racionalmente calculado, em seguida, estabelece um paralelo entre a produção em série do taylorismo e o balé das garotas: "as pernas das Tillergirls correspondem às mãos nas fábricas"25.

Kracauer redigiu entre 1924-25, O romance policial. Um tratado filosófico, só publicado integralmente em $1971^{26}$. O pequeno livro lança luz sobre uma nova forma de literatura, que se tornará depois o tipo de literatura de entretenimento par excellence, base significativa da produção de Hollywood, o filme policial. Sem se constituir em uma obra de arte em sentido estrito, o romance policial é mais do que um "produto misto" [Mischprodukt], mas um "gênero estilístico determinado"[bestimmte Stillgattung]. A abordagem de Kracauer está influenciada pela Teoria do romance, ao definir o personagem moderno como um "apátrida transcendental", personagem de um mundo desencantado (Weber) e dominado pela ratio, nos seus termos, "uma sociedade civilizada inteiramente racionalizada" [eine durchrationalisierte zivilisierte Gesellschaft] ${ }^{27}$, como também pela confluência das esferas, ético-religiosa, estético-expressiva e lógico-cognitiva, no instante vivido, de matriz kierkegaardiana. Segundo Rainer Rochlitz, "o livro de Kracauer por causa desta concepção estética, amplamente inspirada pela Teoria do romance, ao 'traduzir' as formas e as figuras do romance policial, ao formular o que essas figuras dizem sem o saber"28. No único ensaio publicado desse livro, incluído por Kracauer em 1963 na coletânea de ensaios Das ornament der Masse, "Átrio de hotel", Kracauer aproxima de modo surpreendente três tipos de espaço de objeto de culto: o de uma igreja, o de um átrio de hotel, cenário dileto dos romances policiais, e o de um cine-teatro. Poderíamos acrescentar os estádios, os programas de auditório, os espetáculos das Tillersgirls, etc. O que

25. Ibid. p. 54.

26. KRACAUER, S. Der Detektiv-Roman. Ein philosophischer Traktat. Frankfurt aM: Suhkamp, 1971.

27. Ibid, p. 9.

28. ROCHLITZ, R. Avant-propos.KRACAUER, S. Le roman policier. Paris: Payot, 2001, p.15-16. 
aproxima esses espaços tão díspares é a impessoalidade. Enquanto no primeiro a individualidade desaparece em meio à congregação dos fiéis que lá vão para encontros, no átrio de hotel estão aqueles que lá vão para não encontrar ninguém. "É o cenário para aquele que não procura nem encontra o outro que está sempre sendo procurado (...) Aqui o nada impessoal representado pelo gerente de hotel ocupa a posição do desconhecido, cujo nome a congregação de fiéis reúne"29. O cine- teatro, se lê em $O$ culto da distração, "como os átrios de hotel, são locais de culto do prazer, o seu brilho visa à edificação"30. Aqui surge um novo público, a massa, um público homogêneo cosmopolita que "do diretor de banco aos auxiliares do comércio da diva à datilógrafa - sente do mesmo modo"31. Como se pode observar na sua crítica à ratio, à impessoalidade, ao ornamento, Kracauer antecipa a argumentação do que Adorno e Horkheimer denominaram de Kulturindustrie, em Dialektik der Aufklãrung de 1947. É desse período, em torno de 1926, sua leitura de Geschichte und Klassenbewusstsein.

\section{O conceito de totalidade}

Sua leitura de Geschichte und Klassenbewusstsein, realizada cinco anos, depois é muito diferente da enfaticamente simpática recepção de Theorie des Romans, conforme podemos constatar lendo sua correspondência com Bloch como também com Leo Löwenthal. Inka Mülder-Bach sugere um esquema engenhoso, divido em três pontos básicos, para se compreender a crítica de Kracauer à interpretação do marxismo feito por Lukács, que tento resumir: em primeiro lugar, para Kracauer, que na ocasião estudava intensamente o marxismo, Marx provém muito mais da tradição do materialismo francês, sobretudo Helvetius, do que da tradição do idealismo alemão, de Hegel em primeiro lugar, conforme a

29. KRACAUER, S. Das Ornament der Masse, p. 160.

30. Ibid, p.311.

31. Ibid. p.313. 
interpretação đe Lukács, que, segundo Kracauer, é uma interpretação “que não 'transcende' materialisticamente o 'idealismo vazio e desgastado', mais do que isto, abandona de novo o conteúdo materialista da teoria marxista `a favor de sistematizações formais fixadas pelo idealismo""32. Como acentua Inka Mülde-Bach, Kracauer não tem em mente reduzir a teoria de Marx a um materialismo mecanicista, mas chamar atenção para o mundo sensível, para o "homem realmente individual" [wirklichen individuellen Menschen $]^{33}$. O segundo ponto se refere ao conteúdo de verdade e à postura de Lukács diante da teologia: "A exigência de confrontação do marxismo 'com conteúdos de verdade autênticos' nesta 'exigência atualíssima", acrescenta Mülder-Bach, "Kracauer encontra-se próximo de Bloch"34. Por último, diz respeito ao seu "conceito de totalidade", no qual Kracauer tira conseqüências drásticas: "Não apenas porque desconhece o caráter de descontinuidade e fragmentário da realidade ao reconstruí-la como totalidade fechada, mas porque este desconhecimento significa igualmente o abandono das tendências progressistas da atualidađe" As conseqüências desta crítica, Kracauer as desenvolve em seu ensaio "O ornamento da massa". Finalmente, Mülder-Bach enfatiza corretamente que a crítica de Kracauer não é de caráter político, mas estético, capaz đe restabelecer "uma comunicação com o mundo das coisas tornado fugaz['flüchtig gewordenen Dingwelt]"36.

32. MÜLDER, I. "Siegfried Kracauer Antwort auf Lukács - Versuch einer Rekonstruktion" (dat.), p.5.

33. Mülder-Bach complementa que "uma confrontação com este Leitmotì da filosofia de Lukács quis desenvolver provavelmente no trabalho Sobre o conceito de homem em Marx'. [Über den Begriff des Menchen bei Marx] ...Mas esse estudo antropológico se perdeu". p.9.

34. Ibid, p.6.

35. Ibid. pp.6-7.

36. Ibid p.8. 


\section{Crítica do mundo das coisas}

Em 1929-30, Kracauer reúne uma série de artigos, originalmente publicados no $F Z$, com o título, Os empregados [Die Angestellten $]^{37}$. O pequeno livro recebeu resenhas simpáticas de Ernst Bloch ${ }^{38}$ e de Walter Benjamin ${ }^{39}$. Kracauer mostra como ao longo dos anos vinte, por meio de citações, conversas e observações, em locais e lugares diferentes, na Alemanha - uma admirável análise concreta de uma situação concreta - se constituiu um novo tipo de trabalhador assalariado, os "empregados", e como, nesse período, sua população quintuplicou em relação à classe operária que apenas duplicou o seu número de "trabalhadores". Uma nova quantidade que não se reverteu em uma nova qualidade em termos de uma nova "consciência de classe" (Lukács), ao contrário, trouxe traços de "não contemporaneidade" (Bloch) e de regressão (Adorno). Uma atitude caracterizada pela fuga nas imagens da propaganda e da distração, "uma fuga da revolução e da morte"40. O livro antecipa em vinte anos a obra de Wright Mills, White collar (Colarinho branco).

No ensaio de 1933, "As camadas da população alemã e o Nacional-Socialismo" [Die deutschen Bevolkerungsschichten und der Nationalsozialismus $]^{41}$, escrito durante o seu exílio em Paris, Kracauer tenta esclarecer para o leitor francês como foi possível que mais de 17 milhões de eleitores tenham dado seu voto para Adolf Hitler. Retoma sua análise de Os empregados, destacando o papel das camadas médias nesse processo, o horror diante da proletarização

37. KRACAUER, S. Die Angestellten. Aus dem neuesten Deutschland. Republicado em 1971 em Frankfurt aM: Suhrkamp. Sobre Os empregados como "literatura sociológica"[soziologische Literatur] ver o trabalho pioneiro de Inka Mülder: Siegfried Kracauer -Grenzgänger zwischen Theorie und Literatur. Seine frühen Schriften 1913-1933. J.B. Metzlersche Verlagsbuchhandlung. Stuttgart 1985. S. 115-124.

38. "Künstliche Mitte"in BLOCH, E. Erbschaft dieser Zeit. Frankfurt aM: Suhrkamp, p. 33-35.

39. "Ein Aussenseiter macht sich bemerkbar" in BENJAMIN, W. Gesammelte Schriften. B. III. Frankfurt aM: Suhrkamp, 1980, pp. 219-228.

40. KRACAUER, S. Die Angestellten. Frankfurt aM: Suhrkamp, 1971, p.99.

41. KRACAUER, S. Schriften 5-3. Frankfurt aM: Suhrkamp, 1990. pp. 223-233. 
e o apoio financeiro dos grandes industriais alemães ao NacionalSocialismo ${ }^{42}$; chama atenção para a impotência política dos sociaisdemocratas e dos comunistas em transformar as tendências anticapitalistas dos setores médios da população alemã em energias revolucionárias ${ }^{43}$, nesse aspecto inteiramente de acordo com a análise de Bloch desenvolvida em seu livro Herança deste tempo (1935). Mas o método político da propaganda, sua estrutura, que tipo de realidade veicula e qual a sua função, desenvolvida pelo nazismo é analisado no Exposé: Massa e propaganda [Masse und Propaganda $]^{44}$. Para isto, faz um détour histórico, partindo da crise econômica do pós-Primeira Guerra Mundial e suas conseqüências sociais, se detém na situação do proletariado e dos desempregados e dos sem-teto, se remete à análise de Os empregados e destaca a combinação de racionalização e terror por meio da hipostasiação da massa transformada em mero ornamento. Argumento já presente em seu ensaio $O$ ornamento da massa. $O$ desdobramento de seu raciocínio culmina no longo ensaio de 1942 e posteriormente na intervenção sobre a função da propaganda nos filmes- noticiário, cinejornal (Newsreal) ${ }^{45}$.

\section{A questão do expressionismo}

Foi publicado no final de 2005 um ensaio extremamente importante para a compreensão da concepção estética de Kracauer "Sobre o expressionismo. Essência e sentido de um movimento de época"[Über den Expressioismus. Wesen und Sinn einer Zeitbewegung] $(1918)^{46}$. Kracauer coloca-se de modo crítico diante de um movimento de época, a experiência das vanguardas históricas

42. Ibid Cf., p.228.

43. Ibid. Cf., p.226.

44. Marbacher Magazin 47/1988. Organizado por Ingrid Belke e Irina Renz. Marbach am Necker, 1988, pp. 85-90.

45. KRACAUER, S. From Caligari to Hitler. London: Princeton University Press, 1947. pp.275-307.

46. KRACAUER, S. Frühe Schriften aus dem Nachlass. B.2. Ingrid Belke (Org), Sabine Biebl (Mt). Frankfurt aM: Suhrkamp, 2005, pp. 7-78. 
e do expressionismo alemão em particular. Não partilha da visão entusiasta de $O$ espírito da utopia, de Emst Bloch, também de 1918, por outro lado, está longe das posições antivanguardistas de Lukács dos anos trinta, como também de seu próprio diagnóstico cáustico em relação à trajetória do expressionismo no cinema, em particular, De Caligari a Hitler, do final dos anos 40. É uma posição ambivalente. Expressa esperança em relação a esta nova forma de arte, se posiciona abertamente a favor dessa por se rebelar contra um intelecto já paralisado por uma visão cientificista que ignora a personalidade, o "humano"; sua luta contra a "realidade"; é simpático a seu pacifismo e pela busca da configuração de um ornamento capaz de conter o humano - nesse aspecto se aproxima da análise de Bloch. No entanto, no final do ensaio de mais de 70 páginas, vê o expressionismo como um Übergangserscheinung [fenômeno de transição], que é "mais um grito à ação e à arte do que um grito e uma arte efetivos"47. Suas reflexões estão bem próximas daquelas do ensaio escrito dois anos depois, que também permaneceu inédito e só foi publicado em 1990, A virada do destino da arte [Schicksalswende der Kunst], já percebendo, nesse pequeno ensaio, traços de declínio [Untergang] $]^{48}$ no movimento expressionista. .

Diferentemente da aposta que Bloch faz em relação ao expressionismo ou Benjamin posteriormente em relação ao surrealismo, Kracauer nunca teve como referência em seus juízos estéticos a experiência das vanguardas históricas como padrão. Isto não significa que não reconheça a legitimidade e a importância desses movimentos, muito pelo contrário. A prova cabal disto são suas simpatias em relação ao cinema experimental de Fernand Léger, Alberto Cavalcanti, René Clair, Hans Richter, entre outros, ou seu entusiasmo pelo cinema soviético ${ }^{49}$. Outra questão importante a ser considerada, mesmo que sumariamente, é que Kracauer também

47. Ibid.p.77.

48. KRACAUER, S, Schriften 5-1, pp. 72-78.

49. Ver BELKE, I. "Siegfried Kracauer als Beobachter der jungen Sowjetunion" in KESSLER, M. e LEVIN, Th. Siegfried Kracauer. Neuen Interpretationen Staufenburg Colloquium. Tübigen: Staufenburg V, 1990, pp. 17-38. 
nunca foi um defensor ardoroso da arte autônoma como Adorno ou, mesmo que com outros referenciais, Lukács.

O ensaio dividido em sete capítulos parte do reconhecimento do movimento expressionista como legítimo, como sendo expressão de disposições anímicas de uma sociedade em crise, de uma arte que sofre um processo insanável de estagnação. Ridicularizá-lo na defesa da arte tradicional seria mais do que um mal-entendido, mas um equívoco imperdoável. Em seguida diferencia três tipos de criação artística, a de caráter objetivo e realista, a de caráter subjetivo e a tentativa de equilíbrio entre estes dois momentos. Localizando o expressionismo entre as tendências subjetivo-expressivas e aproximando-o ao movimento do Sturm und Drang. Em seguida, considera a relação da arte com a realidade. Há no expressionismo uma luta contra a realidade, para demonstrar isso, Kracauer realiza um détour histórico que vai da Renascença às vanguardas. Depois analisa a relação com a forma, a tradição e a convenção, aqui fazendo uso das teorias de Wolfflin e Worringer - para não falar de Simmel na construção de todo seu raciocínio, o uso de conceitos como vivência [Erlebnis] etc. Mais adiante analisa a questão do conteúdo e a posição em relação a este, seus exemplos são extraídos da pintura e da dramaturgia expressionista, sobretudo as peças de Georg Kaiser, é quando realiza uma análise imanente das obras e dos procedimentos artísticos do expressionismo, como a cor, a composição, os diálogos, a relação entre material artístico e estilos individuais etc.

O que me parece decisivos desses seus primeiros escritos é que eles lançam uma nova luz para a compreensão da crítica da modernidade estética em Kracauer e de que modo este conjuga visão estética, análise sociológica e teoria da história. Três momentos que se intercalam seja na crítica cinematográfica, como em suas observações sobre as metrópoles - questões de uma atualidade incomum ${ }^{50}$.

50. Não por acaso, a obra de Kracauer passa a ser "descoberta" pelo que se convencionou chamar de cultural studies, ver, por exemplo, o interessante ensaio de Miriam Bratu Hansen, "Estados Unidos, Paris, Alpes: Kracauer (e Benjamin) sobre o cinema e a modernidade" in CHARNEY, L. e SCHWARTZ, V. O cinema e a invenção da vida moderna. São Paulo: Cosac \& Naify, 2001, pp. 497-558. 
Essa posição ambivalente muda ao longo dos anos vinte, o que pode ser percebido em sua crítica cotidiana da produção cinematográfica alemã. O texto de 1928, "Film 1928"51, originalmente com o título de Cinema e sociedade [Film und Gesellschaft], é extremamente representativo, pois Kracauer antecipa sua polêmica interpretação do cinema alemão de 1947, De Caligari a Hitler. Mostra de que modo toda uma produção de qualidades técnicas excepcionais não tinha outro objetivo senão o culto da evasão, da irrealidade, da falta de substância. Antecipando assim o fim medonho que se aproximava - como nas gravuras de Alfred Kubin.

Kracauer analisa certas produções que enfocam a questão da mobilidade social, ou melhor, de que modo indivíduos proletários tornam-se, evocando o Sermão da montanha, "bem-aventurados". "As telefonistas, as balconistas do comércio e as secretárias particulares podem ter esperança, sem necessitar recorrer a seus sindicatos profissionais, pois Lotte, uma simples manicure, não foi a única a ter seu dia de sorte ${ }^{52}$, em Lotte teve o seu dia de sorte [Lotte hat ihr Glück gemacht], [...] Tem que ser bonita, com certeza. O reino do céu para onde estas pessoas escolhidas três vezes seguidas foram transportadas é a sociedade. (...) Certamente, Lotte, que se casou nessa sociedade, teve seu dia de sorte." 53

Em seu exílio parisiense, Kracauer redige uma série de artigos Revendo velhos filmes [Wiedersehen mit alten Filmen] ${ }^{54}$ para a Neue Züricher Zeitung, na qual um deles, publicado no início de maio de 1939, com o título "O cinema expressionista"[Der expressionistische Film], merece nossa atenção. Kracauer toma como exemplo os filmes Caligari de Robert Wiene (1919), Golem de Paul Wegener (1920), Strasse de Karl Grune (1923) e Der letzte Mann de Friedrich Murnau (1924). Todos eles "ilustram representações da loucura e um mundo povoado de formas

51. KRACAUER, S. Das Ornament der Masse, p. 295-310.

52. Filme de Carmen Boni de 1928.

53. Ibid. p. 298.

54. KRACAUER, S. Kleine Schriften zum Film. 1932-1961 Inka Mülder-Bach (Org). Frankfurt aM: Suhrkamp, 2004. pp.266-270. 
fantasmagóricas" [veranschaulichen eine Wahnvorstellungen und Spukgestalten bevölkerte Welt $]^{55}$. Para Kracauer, Fritz Lang, Murnau, Paul Leni, entre outros, dirigiram filmes tomando a mesma orientação: "O que há de comum entre eles é que são encenados numa esfera inteiramente irreal e não deixam de lado qualquer possibilidade de produzir o horror"'(idem). Assim como a preferência pelas lendas antigas povoadas de fantasmas, vampiros, assassinos e loucos. Eles expressam o medo: "Eles encarnam nos ossos o choque da guerra perdida, a guerra que se inflamou no interior, a inflação que arruinou a pequena e média burguesia e quanto mais insegura esta se torna mais se espalha o sentimento incurável de insegurança vital"s6. O mundo exterior aparece como caos, desespero, absurdidade, um pesadelo coletivo que toma conta da população; diante desta confusão generalizada e do medo, eles oferecem a evasão como alternativa, ao contrário de uma confrontação sóbria (nüchtern) com relação à realidade social. Kracauer utiliza não só argumentos semelhantes de sua análise cáustica de seu livro de 1947, mas frases idênticas. Isto é, a Alemanha, diferentemente da Inglaterra e da França, não passou por uma revolução, nunca conseguiu estabelecer uma sociedade verdadeiramente democrática. Os alemães: "ficaram de fora do esclarecimento [Aufklãrung] ocidental, não produziram nem um Balzac nem um Dickens"s7. A irrealidade nos filmes não é decorrente do uso da decoração cênica, decoração inspirada no teatro, precisa Kracauer: "trata-se de uma decoração que é conscientemente irreal, que eleva a pretensão de ser testemunha da alma exaltada. As decorações expressionistas são artificiais, com o significado acompanhado de imagens que exigem que sejam observadas enquanto tais e, a obrigação da câmera em relação a elas, é então de criá-las e de fotografá-las" ${ }^{\text {"58 }}$. Uma decoração que, se apoiando em Iris Barry, encontra seu lugar adequado no teatro, não sendo especificamente cinematográfica. Todo um conjunto de produção de filmes que se

55. Ibid. p.266.

56. Ibid. p.267.

57. Ibid. p.267.

58. Ibid. p.269. 
seguiu aos primeiros filmes expressionistas, por meio de uma movimentação da câmara que capta detalhes estranhos da realidade, que tem como característica representar um cotidiano que se torna irreal. É a evasão, conforme Kracauer pontua no seu ensaio anterior Film 1928, e conclui: "Não fotografam alucinações pintadas, mas descobrem que toda coisa viva pode se tornar alucinação; não desprezam o exterior por causa do efeito anímico, mas atualizam como o exterior às responde" 59 .

Voltando ao ensaio Film 1928, nele Kracauer se coloca radicalmente crítico diante da maioria dos filmes até então produzidos, certamente sem deixar de mencionar exceções. Quase todos têm como característica a falta de substância[Substanzlosigkeit], a evasão: "A falta de substância é a característica decisiva do conjunto da produção cinematográfica estabelecida"60. É justamente esta ausência de conteúdo o calcanhar de Aquiles do filme Berlin Filmsymphonie de Ruttmann: "Uma obra sem ação propriamente que permite que a metrópole surja como resultado duma seqüência de caminhos microscópicos individuais. Comunica a realidade de Berlim? (...) A causa disto é política"61. São no mínimo curiosas essas observações de Kracauer sobre Ruttmann, escritas em 1928, que posteriormente se tornará um cameraman dos newsreals de Hitler, até ser morto na frente leste. Pois estão plenamente de acordo com sua analise posterior sobre os newsreals de propaganda de guerra nazista, $A$ conquista da Europa na tela. $O$ cine-jornal nazista 1939-40 [The conquest of Europa on the screen. The Nazi Newsreal 1939-40], de 1943: "O mesmo desejo [de evasão, CEJM] se mostra ativo em Sinfonia de Berlim de Ruttmann como uma composição silenciosa tardia que conecta múltiplas tomadas de cena do cotidiano de Berlim num rítmo tal como se esta vida parecesse ser exibida por si mesma na tela". E

59. Ibid. p. 270.

60. KRACAUER, S. Das Ornament der Masse. Op cit., p. 308.

61. Ibid. pp.307-308. 
acrescenta: "Ruttmann continuou a trabalhar sob Hitler até ser morto na Russia"62.

Em seus ensaios do final dos anos vinte e do início dos anos trinta, Kracauer manifesta uma lucidez incomum em relação ao fim catastrófico que vai abater a sociedade alemã, pondo fim à república de Weimar com a ascensão do Nacional-Socialismo em 1933. Expressa uma força crítica premonitória. Posteriormente, Kracauer mostra em detalhes de que maneira o nazismo vai se apropriar do que havia de melhor na tradição cinematográfica alemã no modo de utilizar a câmera, nos corte, na montagem, na edição etc. O papel da propaganda visual: "Enquanto os alemães da era pré-Hitler empregavam estas técnicas para conquistar mais e mais terrenos do mundo visual, os Nazis as utilizam com intenções bem diversas. Ao enfatizarem o papel do visual eles empregam estes efeitos ... com a intenção de reprimir o intelecto e de afetar diretamente a vida emocional. A predominância da imagem visual no cine-jornal nazista é sinônima com o mínimo de explanação verbal"63.

O que esses comentários de Kracauer tem a ver com o Die Expressionismodebatte, ocorrido na revista Das Wort ao longo de 1938 ? Diretamente muito pouco, como se sabe, e Bloch é uma boa testemunha, Kracauer durante seu exílio teve uma participação política quase nula, pois temia pela situação de sua mãe e de sua tia que ficaram na Alemanha e que, em 1942, foram deportadas pelos nazistas para o campo de extermínio em Theresienstadt ou para a Polônia, conforme relata $\mathrm{Bloch}$, em depoimento $\mathrm{K}$. Witte, sobre a dificuldade de manter contato pessoal com ele no período (TEXT UND KRITIK, 1980). Indiretamente muito e podemos afirmar que Kracauer tinha conhecimento de toda a discussão desde o início na revista Die Linkskurve (ver carta de Löwenthal a Kracauer, de 20/10/1932), da publicação de Herança deste tempo, de Bloch no final de 1934 (ver Bloch Briefe). Da polêmica em Das Wort, não podemos comprovar.

62. KRACAUER, S. The conquest of Europa on the screen. The Nazi Newsreal 1939-40. Washington: Library of Kongress, 1943 (dat). p. 16.

63. Idem. 
A questão central de Kracauer de sua crítica ao cinema alemão do período da República de Weimar é o irrealismo, o caráter evasivo, a falta de conteúdo etc. Nesse sentido mutatis mutandis, para Kracauer também trata-se do realismo [Es geht um Realismus], conforme o célebre texto de Lukács de $1938^{64}$. Kracauer jamais saiu na defesa do expressionismo como fizera Bloch. O próprio Benjamin, na sua Passagenwerk, chama atenção que Lukács foi o primeiro a perceber a relação entre a Weltanschauung expressionista e o fascismo: "Aqui não se pode perder de vista as relações que Lukács estabeleceu entre expressionismo e fascismo" $(\mathrm{N} 8 \mathrm{a}, 1)^{65}$. Certamente há profundas diferenças de opinião e de objeto. Lukács só de forma episódica ${ }^{66}$ analisou a produção cinematográfica e nem sempre teve sensibilidade em considerar tecnicamente a produção das vanguardas históricas, diferentemente de Kracauer que sempre valorizou a excelente qualidade técnica de alguns filmes alemães. Ambos defendem o realismo, mas o de Lukács está centrado no realismo crítico francês e russo do século XIX, ou seja, na literatura. A diversidade deve ser ressaltada, Kracauer além de exaltar o cinema experimental soviético e francês era profundo admirador de Kafka. Kracauer defende o realismo no cinema, seguramente, basta lembrar seu entusiasmo pelo neo-realismo italiano, mas é, como lembra Adorno, "o realista bizarro". Outra questão importante é o 1848 francês.

64. Sobre esta polêmica na Das Wort. MACHADO, C.E.J. Debate sobre o expressionismo. Um capitulo da modemidade estética. São Paulo: Ed. UNESP. 1998

65. BENJAMIN, W. Das Passagen-Werk.B.1. Rolf Tiedmann (Hsg). Frankfurt aM: Suhrkamp, 1983, p.590

66. Lukács cita positivamente o livro de Kracauer, de 1947, a única referência sobre Kracauer, acredito, quando analisa de que modo tendências sociais são repostas no cinema: "Para o cinema alemão entre o final da Primeira Guerra Mundial e a ascensão de Hitler ao poder Kracauer formulou bem \{gut dargestellf] esta questão" LUKACS, G. Die Eigenart des Ästhetischen. B.2. Neuwied: Luchterhand, 1963, p.515. E provavel que Lukács tenha tido conhecimento deste célebre livro de Kracauer através do historiador e crítico de cinema italiano Guido Aristarco, muito próximo da concepção de "realismo crítico" de Lukács. Infelizmente este capitulo foi excluido da versão resumida realizada por Ferenc Feher no início dos anos 70. 


\section{Quando les capacités de la bourgeoisie s'en vont (Marx)}

No final de 1934, Kracauer inicia a redação de uma biografia da época do Segundo Império, Jacques Offenbach e Paris de sua época [Jacques Offenbach und Das Paris seiner Zeit], com a esperança de obter algum sucesso internacional. O livro foi publicado em Amsterdã em 1937 e em seguida traduzido para o francês e inglês. A repercussão do livro foi nula e foi também muito mal recebido pelos amigos mais próximos, como Adorno e Benjamin. As reflexões de Kracauer sobre as cidades, que em parte são anteriores ao exílio parisiense e de importância-chave para se compreender seu propósito de elaborar uma "biografia da sociedade", ou seja, uma biografia da cidade de Paris durante o Segundo Império. Não se trata apenas de mais uma biografia sobre Offenbach e de sua produção musical, justamente por esta razão não se coloca para ele como imprescindível uma análise do material musical das operetas de Offenbach. Questão que gerou e continua a gerar mal-entendidos sobre esse seu importante trabalho ${ }^{67}$. Trata-se de analisar o que o autor entende pelo conceito de "biografia da sociedade". Assim se expressa Kracauer no préfacio: que seu livro se distingue da forma tradicional da biografia de um autor, em geral centrada na sua vida privada, pois pretende realizar uma "biografia da sociedade":

França, ou mais precisamente, Paris. Como cenário de uma sucessão ininterrupta de acontecimentos sociais, políticos e artísticos de primeira linha. Paris do século $X I X$ é a única cidade cuja história é ao mesmo tempo a história da Europa. Este livro, portanto, deve ser considerado ao mesmo tempo como a biografía de uma cidade. É um ensaio sobre a vida de Paris que, partindo

67. GRIMSTADT, K. "Jacques Offenbach. Reflex und Reflexion eines Phänomens bei Kart Kraus und Siegfried Kracauer" in KESSLER,M. u. LEVIN, Th. Siegfried Kracauer. Neue Interpretationen, . pp.59-76. 
de Louis Philippe para terminar com o começo da Terceira República, detendo-se particularmente no periodo de Napoleão III. Por outro lado, é irrefutável que os acontecimentos da presente hora conferem $\dot{a}$ fantasmagoria do Segundo Império certa atualidade ${ }^{68}$.

Nesse trecho da Introdução, Kracauer se refere à "fantasmagoria do Segundo Império" no mesmo sentido que Benjamin em seu Exposé, "Paris capital do século XIX": "A fantasmagoria da cultura capitalista alcança o seu desdobramento mais brilhante na Exposição Universal de 1867 . O Império está no apogeu do seu poder. Paris se afirma como a capital do luxo e da moda. Offenbach prescreve o ritmo da vida parisiense. A opereta é a irônica utopia de um duradouro domínio do capital". 69 . O conceito de "fantasmagoria" é decisivo para se compreender o conjunto expositivo tanto da Obra das passagens como do livro sobre Offenbach. Trata-se de um desdobramento original de Benjamin e de Kracauer do conceito de "fetichismo da mercadoria" (Marx), como também do conceito de reificação (Verdinglichung) de Lukács de História e consciência de classe $^{70}$.

Como mostra Enzo Traverso ${ }^{71}$, poder-se-ia reler a história do século XX sob o prisma do exílio. Um exílio não só social e político, mas também intelectual, no caso de Kracauer e Benjamin, é um exílio que começa no próprio país de origem, a Alemanha, da passagem do século XIX ao XX. Tipificam o que o jovem Lukács denominou

68. KRACAUER, S. Jacques Offenbach und das Paris seiner Zeit.. Werke B. 8. Ingrid Belke (Hsg). Frankfurt aM : Suhrkamp, 2005. pp.11-12.

69. BENJAMIN, W. Das Passagen-Werk, p. 51-53.

70. Sobre a relação de Benjamin com a teoria do fetichismo da mercadoria de Marx e a versão lukacsiana da reificação social ver a introdução de Rolf Tiedemann à Passagen-Werk (BENJAMIN, W. 1983, pp.25-25).

71. TRAVERSO, E., La pensée dispersée. Paris: Lignes, 2004. Sobre a questão do exilio ver também: MÜLDER-BACH, I. "Mancherlei Fremde. Paris Berlin und die Exterritorialität Siegfried Kracauers" in Juni-Magazin für Kultur \& Politik. 1989, pp. 61-72; JAY, M. Permanent Exiles. New York: Columbia University Press, 1986. 
de "apátrida transcendental" - Lukács que também passou pela mesma experiência durante a II Guerra Mundial, exilando-se em Moscou de 1933 a 1944. É a experiência - usando a expressão de Kracauer - da "exterritorialidade"; são intelectuais "nômades". Quando Kracauer elege Offenbach como objeto de análise, há algo de autobiográfico, ao tomar a trajetória de um apátrida. $O$ que dizer do destino de Heinrich Heine e Karl Marx no século XIX? O próprio Kracauer utiliza a expressão, no magnífico capítulo sobre os bulevares parisienses, A pátria dos apátridas [Die Heimat der Heimatlosen].

Boa parte da intelectualidade de esquerda da época, anos trinta, como Benjamin, Kracauer, Bloch e também Lukács, vê a segunda metade do século XIX, sobretudo na França, como a forma originária (Urform, Benjamin) da modernidade, da sociedade de massas e, particularmente, do nazi-fascismo, atualizando o diagnóstico de Marx desenvolvido no Dezoito Brumário: o Segundo Império como uma farsa ${ }^{72}$. Quando les capacités de la bourgeoisie s'en vont. Um diagnóstico de extrema atualidade, pois é justamente quando se instaura historicamente pela primeira vez um estado de sitio, a condição política dos "exterritoriais" como "apátridas transcendentais" e que hoje se reveste de uma terrificante forma mundializada ${ }^{73}$.

72. Ver $O$ instigante e elucidativo ensaio de Olivier Agard: "Jacques Offenbach ou l'archéologie de la modernité"in PERIVOLAROPOULOU, N. DESPOIX, Ph. Culture de masse et modernite. Paris: Sciences de l'Homme, 2001. pp.179-211.

73. Ver "Estado de sítio" in ARANTES, P. E. Extinção. São Paulo: Boitempo, 2007, pp.153-166. 